Research Article

\title{
A Simplified Model for Hysteretic Nonlinear Dynamic Response Analysis of Concrete Covering Grouting
}

\author{
CHEN Juan ${ }^{1}$, XU Lisheng ${ }^{1}$, ZHANG Fan ${ }^{2, *}$ and XU Meng ${ }^{1}$ \\ School of Physics and Earth Science Information, Central South University, Changsha 410083, China \\ ${ }^{2}$ School of Mechanical and Electrical Engineering, Central South University, Changsha 410083, China
}

Received 15 June 2013; Accepted 23 March 2014

\begin{abstract}
Based on the fundamental conception of hysteretic systems random vibration, this paper presents a simplified model to analyze the hysteretic nonlinear dynamic response of concrete covering consolidation grouting. The proposed model aims at capturing the hysteretic characteristics of the concrete covering nonlinear behavior and revealing the importance of grouting pressure dynamic load affecting the concrete covering uplift behavior. To this end, the proposed approach considers the concrete covering as Bernoulli-Euler beam, and then incorporating the Bouc-Wen model, simulates the soil force on the concrete covering, the one that beneath the concrete covering can be considered as hysteresis spring and dashpot in parallel. According to the actual grouting parameters, amplitude-frequency response characteristics of concrete covering are discussed under different external load. A comparison of model calculation results and real-field experiments are used to evaluate the effectiveness of the presented method, the results show that the predictions of the model correspond with the measured values.
\end{abstract}

Keywords: grouting; uplift behavior; nonlinear dynamic response; Bouc-Wen model; concrete covering

\section{Introduction}

The concrete covering uplift behavior during consolidation grouting is a major contributor to concrete covering cracking, which weakens the anti-seepage properties of the dam. Related studies have shown that there were significant correlation between uplift displacement and grouting pressure in grouting process [1-2]. Unstable grouting pressure is affected by many factors, such as various rocks structural surfaces, grouting methods, fracture aperture and grouting performance [3]. At present, uplift displacement control is primarily done with real-time sensors. In the presence of lag effect, these sensors may not accurately predict uplift displacements. Gonzalez et al [4] presented a general analytical solution to the ground deformation during the construction of the Madrid Metro extension plan. Based on this research, Gollegger [5] introduced a solution to displacement field caused by compensation grouting.

Hysteresis is a typical nonlinear phenomenon widely encountered in the field of civil engineering [6-7]. In the presence of uplift effect, reducing the grouting pressure will not immediately decrease the uplift displacement. The changes of uplift displacement typically lag behind the grouting pressure changes. Therefore, investigating the hysteretic effect of concrete covering uplift during grouting process is essential for the control of concrete covering uplift deformation and thus ensuring the engineering construction quality. Ma et al [8] presented a system

\footnotetext{
*E-mail address: Happyzf2005@163.com

ISSN: 1791-2377@ 2014 Kavala Institute of Technology. All rights reserved.
}

identification method to predict the response of a degrading structure based on Bouc-Wen differential model. Zhang et al [9] developed a numerical model to evaluate the uplifting effect for upper structure by grouting. The studies in the above mainly focus on the uplift displacement modeling and simulating in grouting processes. Currently, there are few studies on hysteretic behavior of concrete covering consolidation grouting. The main objective in this paper is to capture the hysteretic characteristics of the concrete covering nonlinear behavior and reveal the importance of grouting pressure dynamic load affecting the uplift behavior of concrete covering. The Bernoulli-Euler beam hypothesis is assumed and the Bouc-Wen model is adopted to simulate the hysteresis spring and the dashpot in parallel. According to the actual grouting parameters, the amplitude-frequency response characteristics of concrete covering are discussed under different external load.

\section{A simplified analysis model of concrete covering}

\subsection{Uplift deformation of concrete covering grouting}

Consider the concrete covering with distributed reinforcing meshes as a linear elastomer. When the grouting pressure reaches to a certain level, on account of the soil volume expansion, it will form an inverted frustum-shaped shear plane upon the grouting slurry. The concrete covering will be elevated, when the uplift force $P$ overcomes the inverted frustum soil gravity $G_{t}$ and the inverted frustum side surface shear force $F_{t}$. Stress analysis of concrete covering and soil during uplift deformation is shown as Fig.1. 


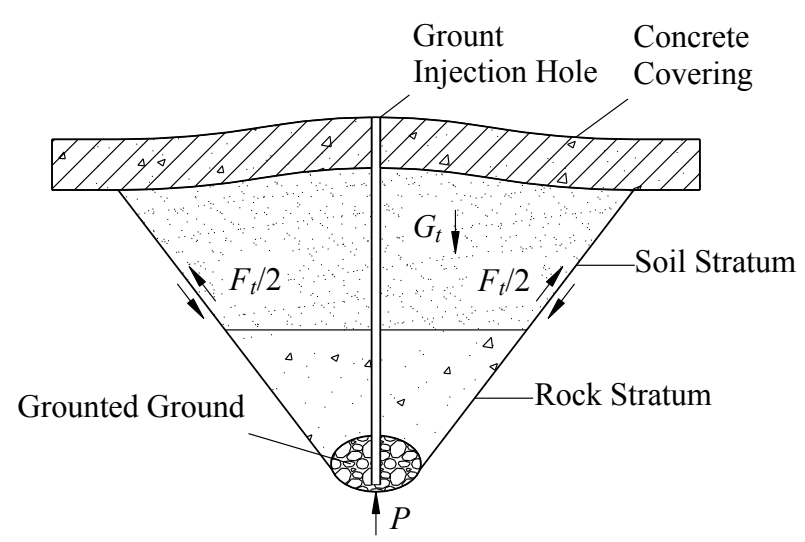

Fig. 1 Stress analysis of concrete covering lifting deformation

The foundation under the concrete covering is considered as soil stratum and rock stratum respectively. The distribution forms of grouting pressure dynamic loads acting on concrete covering through the rock and soil not only are related to the natural fracture zones in rock seam; the groundwater; and the geotechnical characteristics but also to the displacement and displaceable manner of rock; the hysteretic effect of soil deformation; and other factors. The observed grouting pressure is often uncertain; timevarying and nonlinear. Due to the allowable displacement of concrete covering is relatively small, the grouting pressure is assumed evenly distributed in the soil. Theoretically, the uplift force exert on soil by evenly distributed grouting pressure is calculated as [10]

$$
P=P_{c}-\frac{6 \mu_{0} Q}{\pi b^{3}} \ln \frac{r}{r_{c}}
$$

where $P_{c}$ is the grouting pressure of grouting hole; $\mu_{0}$ is the kinematics viscosity slurry; $b$ is the crack width; $r$ is the radius of the slurry diffusion; $r_{c}$ is the grouting hole radius and $Q$ is the amount of grouting.

Inverted frustum soil gravity $G_{t}$ and inverted frustum side surface shear force $F_{t}$ exert upon the slurry are separately calculated as [11]

$$
\begin{aligned}
& G_{t}=\frac{\pi \gamma h}{3 \tan ^{2} \theta}\left[3 h^{2} \tan ^{2} \theta+2 r_{b} h \tan \theta+h^{2}\right] \\
& F_{t}=2 G_{t} \frac{1-\sin \theta \cos [\pi-(\theta+\varphi)]}{\cos \varphi \sin \theta}
\end{aligned}
$$

where $h$ is the height of inverted frustum soil, $h=0.5(B-2 r) \tan \left(\theta+\frac{\varphi}{2}\right) ; B$ is the maximum span of concrete covering displacement area; $r_{b}$ is the radius of grouting sphere; $\theta$ is the angle between the horizontal plane and shear surface; $\varphi$ is internal friction angle of soil; $\gamma$ is the soil specific weight.

\subsection{Basic parameters of the concrete covering grouting} model

Since the vibration of concrete covering is along the vertical direction, the influence of width can be ignored and the concrete covering grouting model is simplified as onedimensional beam structure. Based on the Bernoulli-Euler beam hypothesis, only the bending stiffness is considered, the shear stiffness and torsional stiffness are ignored. As shown in Fig. 2, the concrete covering was seem as a cantilever beam, the basic parameters of the beam were: $\rho_{m}$ is the material density; $A_{s}$ is the concrete covering crosssectional area; $E_{e p}$ is the elastic modulus; $k_{m}$ is the stiffness coefficient; $L$ is the length of the concrete covering; $I$ is the moment of inertia, $I=L h_{1}{ }^{3} / 12 ; h_{1}$ is thickness of the concrete covering. The above constants are assumed the same along the longitudinal direction. The foundation under the concrete covering is considered as the Winkler-Kelvin type basis. Hence, the grouting pressure exerted on concrete covering and foundation is a nonlinear force simulated by a nonlinear spring of transient elastic stiffness $k$ of continuous uniform distribution and varied with depth. In parallel with the nonlinear spring was a stick pot whose damping coefficient is $c$. For different soil and rock formations utilized different values of equivalent stiffness and damping with superscript $a$ and $b$ which denoted as $k^{a}, k^{b}$ and $c^{a}, c^{b}$ respectively.

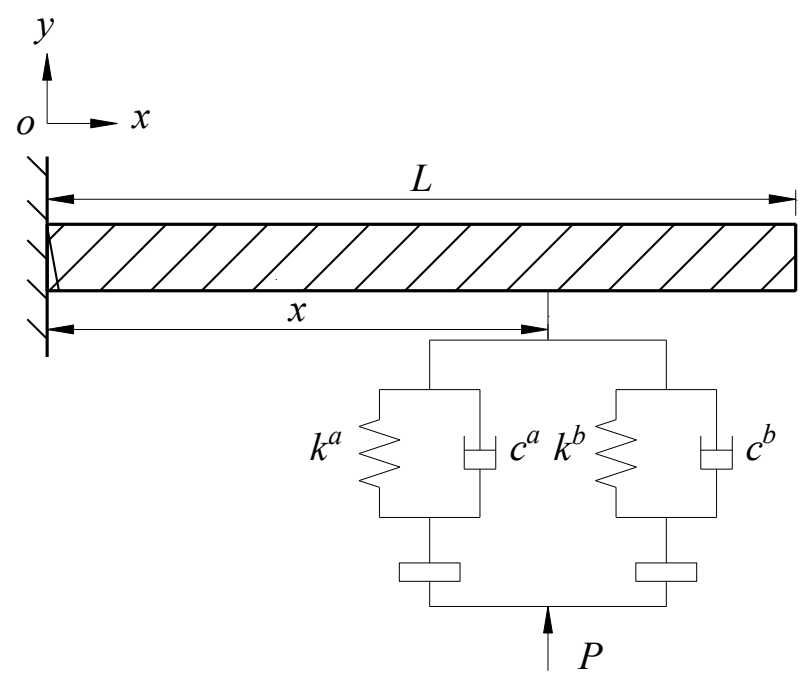

Fig. 2 Simplified Dynamic Model of Concrete Covering Grouting

\subsection{Grouting pressure model}

To simulate the nonlinear hysteretic restoring force of the spring, a degenerative hysteretic model namely degradation Bouc-Wen model is utilized which firstly proposed by Bouc [12] and further developed by Wen [13] and Baber [14]. Assuming the one-dimensional beam deformation equation is $y(x)$, then the continuous distributed spring force at any position $x$ of the concrete covering was given by

$$
F(x)=\alpha k(x) y(x)+(1-\alpha) k(x) \xi(x)
$$

where $\alpha$ is a weighting factor; $\xi(x)$ is the hysteretic displacement variable used to control hysteretic effect which could be described by the following differential equation

$$
\dot{\xi}(x)=a \dot{y}(x)-v\left(\beta|\dot{y}(x)||\xi(x)|^{n-1} \xi(x)+\gamma \dot{y}(x)|\xi(x)|^{n}\right)
$$

where $a$ and $v$ are the parameters measuring the deteriorate characterizing of hysteretic displacement; constants $\beta, \gamma$ and $n$ is dimensionless model parameters to control the shape of the hysteretic loop. In practice, generally take $a=1$ and $v=1$; parameter $n$ affect the smoothness of the hysteretic loop, generally take $1 \leq n \leq 5$ for different geological conditions have different non-linear characteristic; $\beta$ and $\gamma$ used to simulate the material softening 
characteristics under dynamic load, $\beta+\gamma=1$ and generally take $\beta=0.4, \gamma=0.6$.

Considering the soil and rock beneath the concrete covering as different stiffness and damping coefficients, when grouting pressure acting on $x=L$, the spring force is calculated as

$$
\begin{aligned}
& F_{P}(x, t)=\left(c^{a}+c^{b}\right) \frac{\partial y(x, t)}{\partial t}+k^{a}[\alpha y(x, t)+(1-\alpha) \xi(x, t)]+ \\
& k^{b}[\alpha y(x, t)+(1-\alpha) \xi(x, t)]
\end{aligned}
$$

where $c^{a}$ and $c^{b}$ are the equivalent viscous damping of soil and rock respectively; $k^{a}$ and $k^{b}$ are the equivalent stiffness of soil and rock respectively; $\xi(x)$ is the hysteretic displacement variable described by Eq.(5).

The initial stiffness coefficient is calculated as [15]

$k=\frac{4 G L}{1-\mu}$

where $L$ is the length of the foundation; $\mu$ is the Poisson's ratio; $G$ is the shear modulus of the material which calculated by the following formula.

$$
G=\frac{E}{2(1+\mu)}
$$

The initial damping of soil and rock is calculated by the equivalent damping method proposed by Wolf [15].

$c=\frac{L}{V_{s}} k \gamma_{0}$

where $V_{s}$ is the material shear wave velocity; $k$ is the material stiffness coefficient; $\gamma_{0}$ is dimensionless constant factor relate with the linear elastic damper, $\gamma_{0}=0.8$ in this paper.

\section{Hysteretic nonlinear dynamic model of concrete covering}

Based on the simplified analytical model of concrete covering uplift displacement proposed in section 2, the dynamic uplift displacement of concrete covering and foundation can be simplified as the response of nonlinear dynamic analysis of a one-dimensional beam on the nonlinear Winkler-Kelvin-type foundation. Due to the concrete covering position is horizontal, the axial force acting on the concrete covering could be ignored. Under the linear elastic circumstances, according to the onedimensional beam theory to calculate the concrete covering strain energy $U_{V}$ and kinetic energy $U_{T}$ as

$$
\begin{aligned}
& U_{V}=\frac{E_{e p} I}{2} \int_{0}^{L}\left(\frac{\partial^{2} y(x)}{\partial x^{2}}\right)^{2} \mathrm{~d} x \\
& U_{T}=\frac{\rho_{m} A_{s}}{2} \int_{0}^{L}\left(\frac{\partial^{2} y(x)}{\partial t^{2}}\right)^{2} \mathrm{~d} x
\end{aligned}
$$

Then, the work of non-conservative forces can be calculated as

$$
U_{W}=\int_{0}^{L} F_{P}(x, t) y(x) \mathrm{d} x
$$

According to Hamilton's principle, the canonical equation denote as

$\delta \int_{t_{1}}^{t_{2}}\left(U_{V}-U_{T}\right) \mathrm{d} t+\int_{t_{1}}^{t_{2}} \delta U_{W} \mathrm{~d} t=0$

Combining Eq.(12)-(13), the nonlinear dynamic equilibrium equation of concrete covering under external dynamic loads can be calculated as

$$
\begin{aligned}
& E I \frac{\partial^{4} y(x, t)}{\partial x^{4}}+\rho_{m} A_{s} \frac{\partial^{2} y(x, t)}{\partial t^{2}}+\left(c^{a}+c^{b}\right) \frac{\partial y(x, t)}{\partial t}+ \\
& k^{a}\left[\alpha y(x, t)+(1-\alpha) \xi^{a}(x, t)\right]+ \\
& k^{b}\left[\alpha y(x, t)+(1-\alpha) \xi^{b}(x, t)\right]=0
\end{aligned}
$$

where $\rho_{m}$ is the density concrete covering; $A_{s}$ is the cross-sectional area concrete covering; $c^{a}$ and $c^{b}$ are the equivalent viscous damping of soil and rock respectively; $k^{a}$ and $k^{b}$ are the equivalent stiffness of soil and rock respectively, $\xi(x)$ is the hysteretic displacement variable to control hysteretic behavior which described by Eq.(5).

When $x=0, y(0, t)=0$; when $x=L$, the boundary conditions are given as

$E I \frac{\partial^{2} y(L, t)}{\partial x^{2}}+k^{m} \frac{\partial y(L, t)}{\partial x}=0$

$E I \frac{\partial^{3} y(L, t)}{\partial x^{3}}=P-\left(G_{t}+F_{t}\right)$

Considering the hysteretic effects, the nonlinear dynamic equilibrium equation of concrete covering shown as Eq.(14) is often difficult to obtain analytical solutions. In fact, Eq.(14) is a second-order differential equation, which describes a time-invariant control system. In this work, the ODE solver from the MATLAB package is implemented for the numerical integration of Eq.(14) and Eq.(5).

\section{Case study}

The proposed nonlinear dynamical response model is applied to analyze the uplifting effect of Nuo Zhadu Dam plinth consolidation grouting under dynamic loading of grouting pressure. Nuo Zhadu Dam using the clay core rockfill dam design of maximum dam height $261.5 \mathrm{~m}$, through the foundation consolidation grouting can effectively strengthen the anti-penetration capability and durability. Consolidation grouting testing area is selected on the right dam plinth of length $60 \mathrm{~m}$, width $10 \mathrm{~m}$ and thickness $1 \mathrm{~m}$; testing length is $15 \mathrm{~m}$; spacing among grouting holes was $2 \mathrm{~m}$; depth of grouting hole is $5 \mathrm{~m}$; using small diameter drilling; water-cement ratio is $2: 1,1: 1$ and $0.5: 1$. According to the experimental study by Wang et al [16], the ideal grouting pressure fitting expression for dynamic load can be calculated as 


$$
P=P_{c}+\frac{P_{c}}{7.5} \sin \frac{\pi t}{15}
$$

where $P_{c}$ is the settled value of the grouting pressure; $P$ is the measured value of grouting pressure; $t$ is the grouting time.
Grouting parameters of soil stratum, rock stratum and plinth are determined according to the geotechnical conditions and the relevant test data; the shear wave velocity $V_{s}=159 \mathrm{~m} / \mathrm{s}$. According to the fractured rock conditions and the natural fracture zones in rock seam to determine grouting drilling position and observe the uplift displacement, the parameters used in the analysis are shown in Tab. 1.

Tab.le 1. Mechanical parameters of plinth and foundation

\begin{tabular}{|c|c|c|c|c|c|c|c|c|}
\hline \multicolumn{3}{|c|}{ Plinth } & \multicolumn{3}{|c|}{ Soil Stratum } & \multicolumn{3}{|c|}{ Rock Stratum } \\
\hline $\begin{array}{c}\text { MOE } \\
E_{e p} / \mathbf{M P a}\end{array}$ & $\begin{array}{c}\text { Poisson's } \\
\text { ratio } \\
\mu\end{array}$ & $\begin{array}{c}\text { Volume- } \\
\text { weight } \\
\rho / \mathbf{k N} \cdot \mathbf{m}^{-3}\end{array}$ & $\begin{array}{c}\text { MOE } \\
E_{e p} / \mathrm{MPa}\end{array}$ & $\begin{array}{c}\text { Poisson's } \\
\text { ratio } \\
\mu\end{array}$ & $\begin{array}{c}\text { Volume- } \\
\text { weight } \\
\rho / \mathbf{k N} \cdot \mathbf{m}^{-3}\end{array}$ & $\begin{array}{c}\text { MOE } \\
E_{e p} / \mathbf{M P a}\end{array}$ & $\begin{array}{c}\text { Poisson's } \\
\text { ratio } \\
\mu\end{array}$ & $\begin{array}{l}\text { Volume- } \\
\text { weight } \\
\rho / \mathbf{k N} \cdot \mathbf{m}^{-3}\end{array}$ \\
\hline 26480 & 0.167 & 24 & 2540 & 0.35 & 18 & 19300 & 0.38 & 21.5 \\
\hline
\end{tabular}

Influenced by structure surface characteristics of rock stratum and fracture aperture and slurry performance and other factors, the grouting pressure often has uncertain and nonlinear time-varying characteristics. Fig. 3 illustrates the grouting pressure curve in $1.5 \mathrm{MPa}, 2.5 \mathrm{MPa}$ and $4 \mathrm{MPa}$ respectively. According to the presented model, the influence of pressure pulsations on the nonlinear response of the plinth was calculated and compared with the measured values under different grouting pressure.

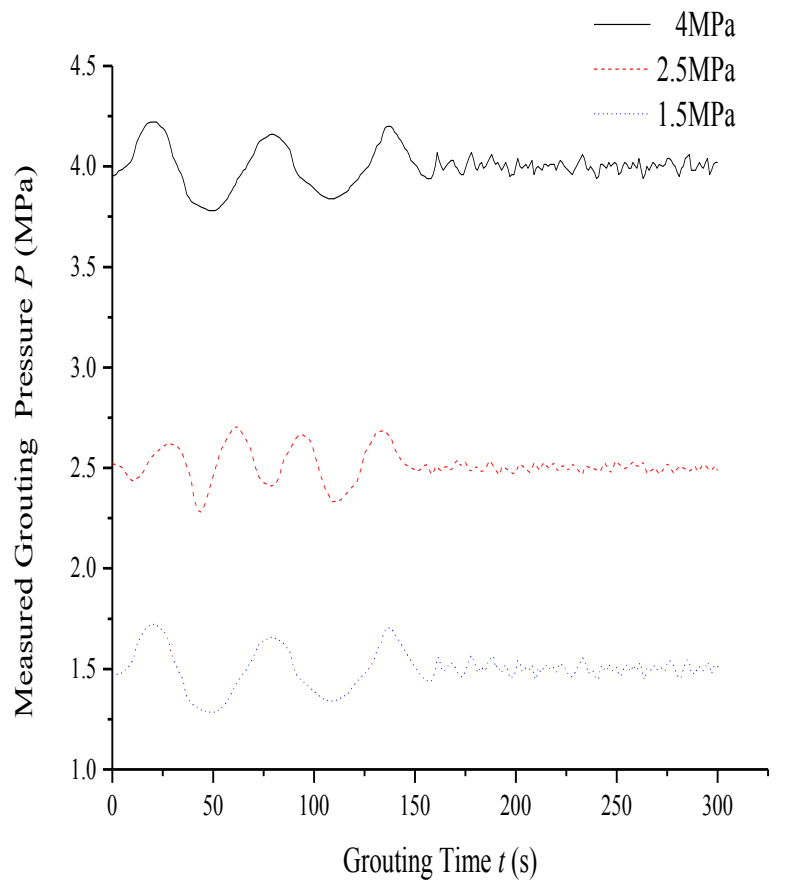

Fig. 3 Measured pressure curves versus time

Fig.4 and Fig.5 show the comparison of measured and calculated values of the plinth uplift displacement when the grouting pressure is $1.5 \mathrm{MPa}, 2.5 \mathrm{MPa}$ and $4 \mathrm{MPa}$ respectively. As can be seen from the figure, the greater the grouting pressures the larger uplift displacement the plinth. At the beginning of grouting, the uplift displacement monotonically increased with time trend and fluctuated with the grouting pressure fluctuations obviously. Uplift displacement under the actual pressure is in good agreement with the displacement under ideal pressure; plinth dynamic response shows significant nonlinear characteristics.

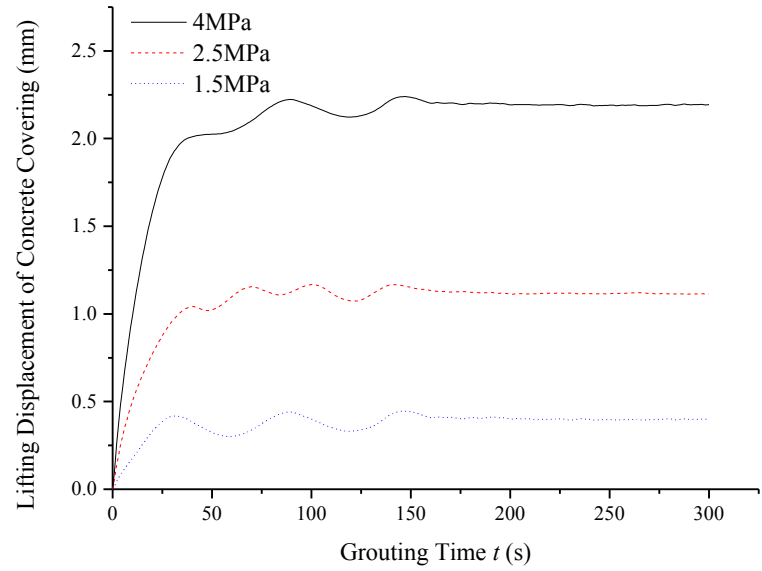

Fig. 4 Lifting displacement of concrete covering under measured grouting pressure

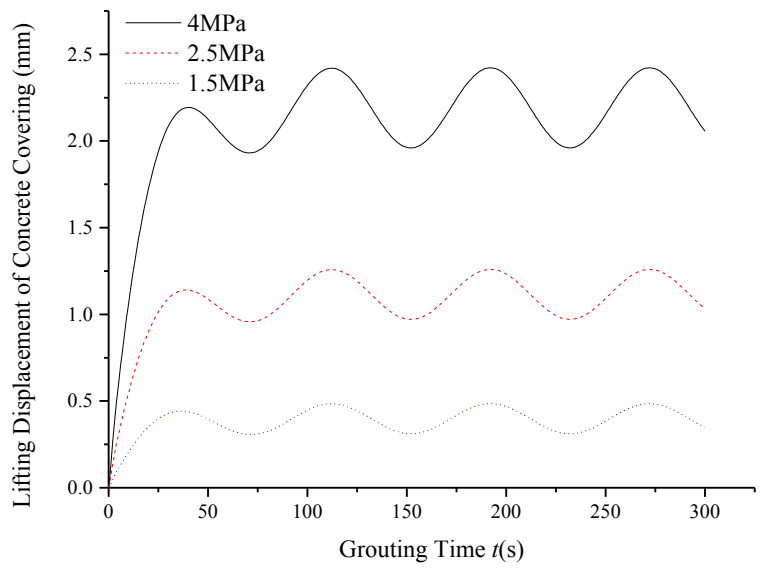

Fig. 5 Lifting displacement of concrete covering under ideal grouting pressure

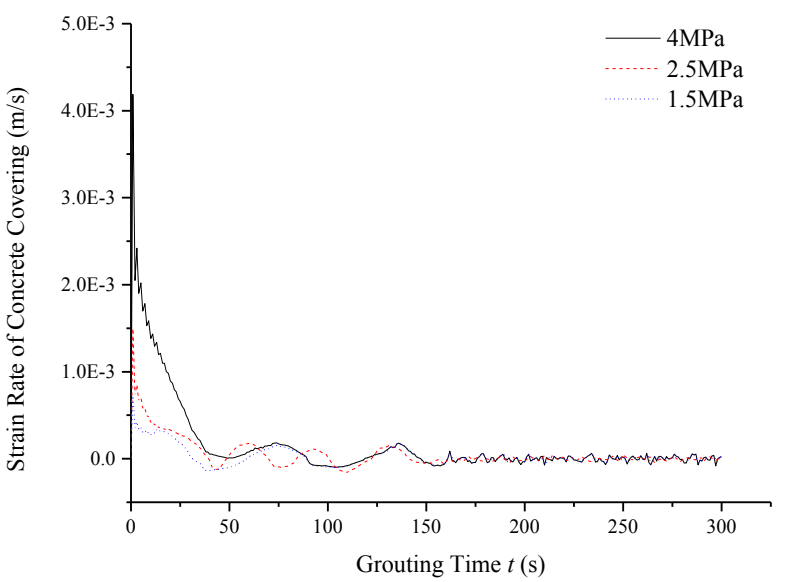

Fig. 6 Lifting strain rate of concrete covering under measured grouting pressure 


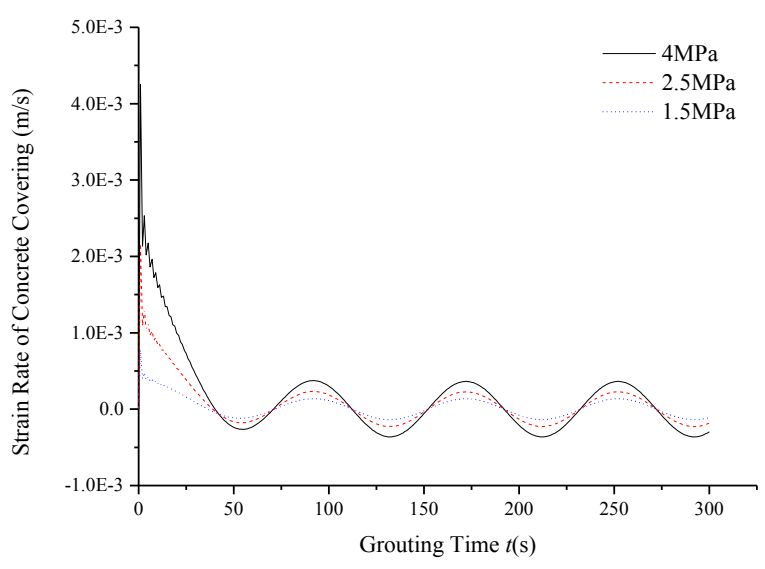

Fig. 7 Lifting strain rate of concrete covering under ideal grouting pressure

Fig.6 and Fig.7 show the comparison of measured and ideal deformation rate of the plinth when the grouting pressure is $1.5 \mathrm{MPa}, 2.5 \mathrm{MPa}$ and $4 \mathrm{MPa}$ respectively. At the beginning of grouting, as can be seen from the figure that plinth deformation rate shows significant disturbance, the greater grouting pressure the bigger amplitude perturbation, then the deformation rate stabilized. The reason is that the plinth uplifting displacement changes significantly with the increase in grouting pressure at the beginning of grouting. When the grouting pressure fluctuation amplitude decreases, the perturbations of panel deformation rate decrease accordingly.

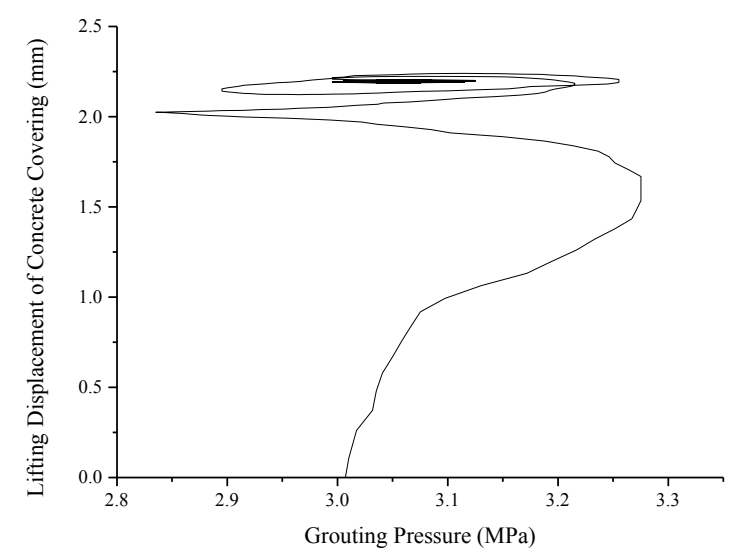

Fig. 8 Dynamic load and displacement under measured grouting pressure (4MPa)

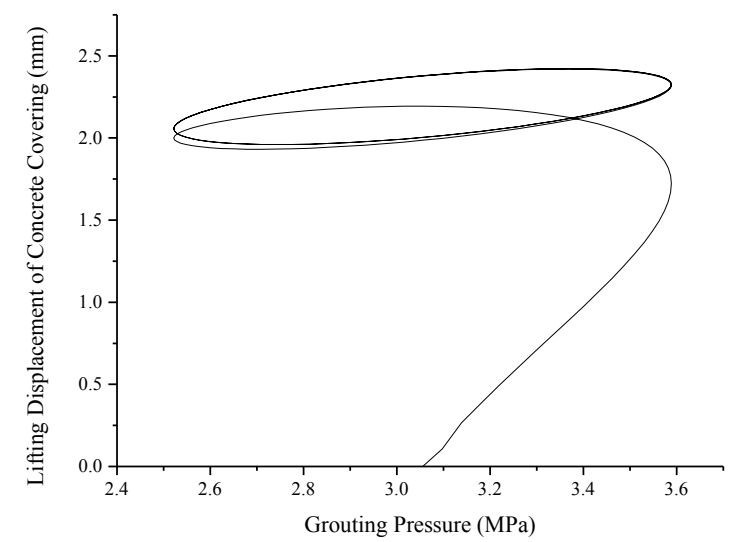

Fig. 9 Dynamic load and displacement under ideal grouting pressure $(4 \mathrm{MPa})$

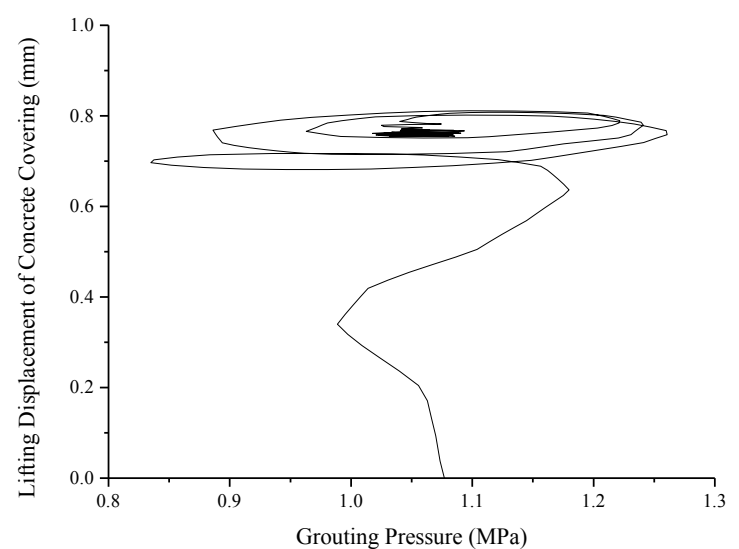

Fig. 10 Dynamic load and displacement under measured grouting pressure (2.5MPa)

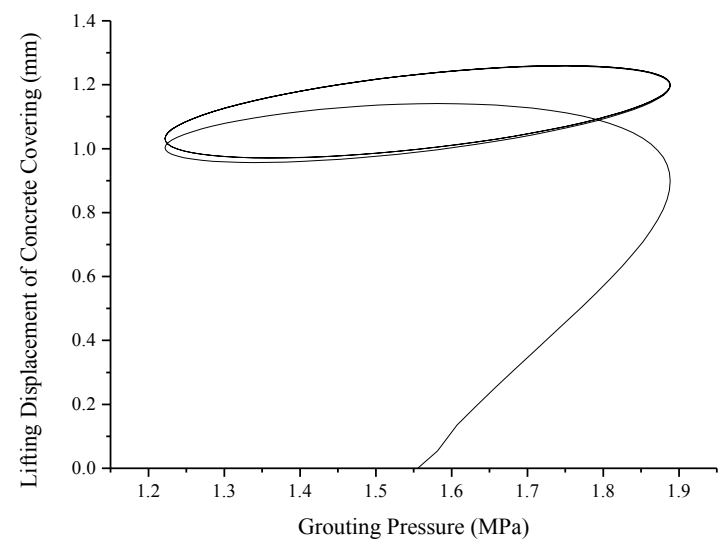

Fig. 11 Dynamic load and displacement under ideal grouting pressure $(2.5 \mathrm{MPa})$

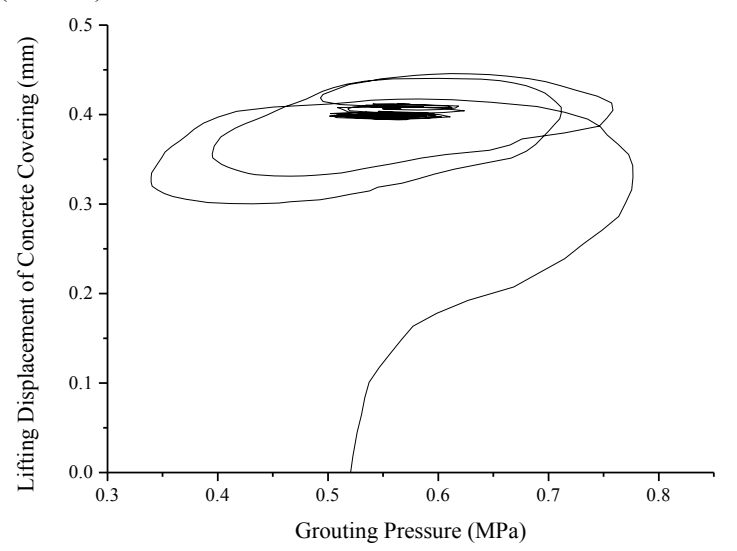

Fig. 12 Dynamic load and displacement under measured grouting pressure $(1.5 \mathrm{MPa})$

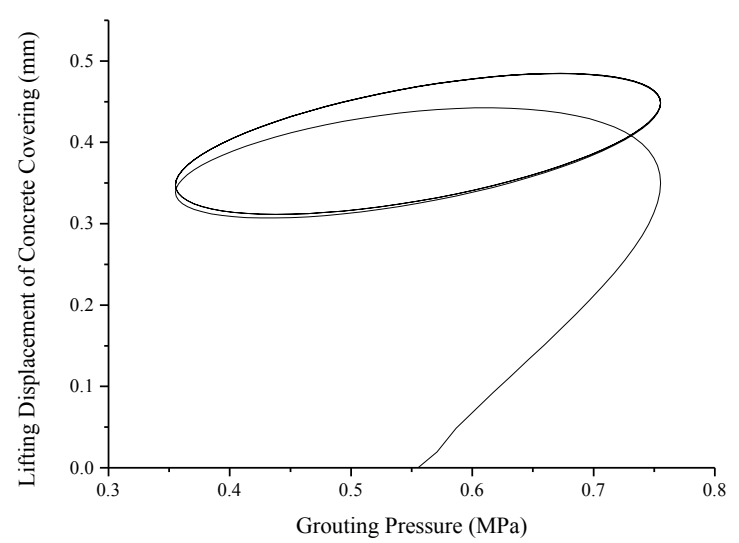

Fig. 13 Dynamic load and displacement under ideal grouting pressure $(1.5 \mathrm{MPa})$ 
Fig. 8 to Fig. 13 show the hysteretic nonlinear response curve of plinth uplift displacement under measured and ideal grouting pressure when grouting pressure is $4 \mathrm{MPa}, 2.5 \mathrm{MPa}$ and $1.5 \mathrm{MPa}$. As can be seen from the figure, there is an obvious hysteretic effect between uplift displacement and dynamic load. With the appearance of uplift effect, reducing the grouting pressure will not immediately decrease the uplift displacement. The plinth uplift displacement lag behind the grouting pressure changes. Therefore, through real-time monitoring of grouting pressure, plinth deformation can be predicted and pre-controlled.

\section{Conclusion}

Based upon the fundamental conception of the random vibration of hysteretic systems, a simplified nonlinear dynamic response model of concrete covering was presented by considering the soil and rock under the concrete covering as spring and dashpot. Taking the plinth consolidation grouting of Nuo Zhadu Dam for an example, the relationship between plinth uplift displacement, strain rate, the dynamic load and uplift displacement under dynamic loads of grouting pressure were analyzed. The results show that

(1) The greater the grouting pressure the larger the uplift displacement. At the beginning of grouting process, the uplift displacement monotonically increased with time and oscillated with the grouting pressure fluctuations obviously. Uplift displacements under the actual pressure are in good agreement with the displacement under ideal pressure, plinth dynamic response shows significant nonlinear characteristics.

(2) Since the uplift displacement obviously amplified with the increasing grouting pressure, concrete covering deformation rate has obvious perturbation at the beginning of grouting process, the greater the grouting pressure the bigger the magnitude of the disturbance.

(3) Under dynamic load of grouting pressure, the nonlinear response of concrete covering consolidation grouting shows significant hysteretic characteristics with the grouting pressure changes. Through real-time monitoring of grouting pressure, it can achieve the prediction and precontrol of the plinth deformation so as to ensure the concrete covering deformation in the controllable range which provides a reference method to control concrete covering uplift displacement under grouting dynamic load.

\section{References}

1. Sagaseta C, "Analysis of undrained soil deformation due to ground loss", Geotechnique, 37(3), 1987, pp. 301-320.

2. Scheweiger H F, Kummerer C, "Numerical modeling of settlement compensation by means of fracture grouting", Soils and Foundations, 44(1), 2004, pp. 71-86.

3. Yang X L, Zou J F, "Estimation of compaction grouting pressure in strain softening soils", Journal of Central South University of Technology, 16(4), 2009, pp. 653-657.

4. Gonzalez C, Sagaseta C, "Patterns of soil deformations around tunnels. Application to the extension of Madrid Metro", Computers and Geotechnics, 28(6-7), 2001, pp. 445-468.

5. Gollegger J, "Numerical and analytical studies of the effects of compensation grouting", Austria: Graz University of Technology, 2001.

6. Khalili N, Habte M A, Zargarbashi S, "A fully coupled flow deformation model for cyclic analysis of unsaturated soils including hydraulic and mechanical hystereses", Computers and Geotechnics, 35(6), 2008, pp. 872-889.

7. Javadi A A, Elkassas A S I, "Numerical modeling of hydraulic hysteresis in unsaturated soils". Transport in porous media, 85(2), 2010, pp. 521-540.

8. Ma F, Ng C H, Ajavakom N, "On system identification and response prediction of degrading structures", Structural Control and Health Monitoring, 13(1), 2006, pp. 347-364.
9. Zhang M, Wang X, Wang Y, "Numerical evaluation of uplifting effect for upper structure by grouting", Journal of Central South University, 19, 2012, pp. 553-561.

10. Zou J F, Li L, Yang X L, "Penetration radius and pressure attenuation law in fracturing grouting", Journal of Hydraulic Engineering, 37(3), 2006, pp. 314-319. (in Chinese)

11. Wang G G, Du M F, Miao X C, "Mechanism of compaction grouting and effect examination", Chinese Journal of Rock Mechanics and Engineering, 19(6), 2000, pp. 670-673. (in Chinese)

12. Bouc R, "Modele mathematique d'hysteresis", Acustica, 21, 1971, pp. 16-25. (in French)

13. Wen Y K, "Method for random vibration of hysteretic system", Journal of Engineering Mechanics Division, 102(2), 1976, pp.249263.

14. Baber T T, Wen Y K, "Random vibration of hysteretic, degrading systems", Journal of the Engineering Mechanics Division, 107(6), 1981, pp. 1069-1087.

15. Wolf J P, "Soil-structure interaction analysis in time domain", Englewood Cliffs, New Jersey: Prentice-Hall, 1988.

16. Wang $\mathrm{C}, \mathrm{Xu} \mathrm{L} \mathrm{S}$, Yao $\mathrm{C} \mathrm{X}$, "Design and simulation of grouting pressure stabilization control system", The Chinese Journal of Nonferrous Metals, 23(9), 2013, pp. 2704-2711. (in Chinese) 